\title{
Upcoming Events in Pediatric Cardiology
}

July 18-22, 2010

Pediatric Interventional Cardiology Symposium-AICS

Chicago, IL, USA

http://www.picsymposium.com

October 30-November 4, 2010

Vancouver, BC, Canada

Annual Scientific Assembly, American College of Chest

Physicians

Telephone: 847/498-1400

http://www.chestnet.org/CHEST

November 13-17, 2010

Chicago, IL, USA

Scientific Session, American Heart Association

http://scientificsessions.americanheart.org
January 31-February 2, 2011

San Diego, CA, USA

Annual Meeting of the Society of Thoracic Surgery http://www.sts.org

April 3-5, 2011

New Orleans, LA, USA

American College of Cardiology, Annual Scientific Session

http://www.acc.org

May 7-11, 2011

Philadelphia, PA, USA

American Association of Thoracic Surgery, Annual Meeting

http://www.aats.org 